RPP-RPT-37508, Rev. 0

\title{
Tank 241-AN-102 Multi-Probe Corrosion Monitoring System Project Lessons Learned
}

\author{
Tom Taylor and Alan Hagensen \\ ARES Corporation for CH2M HILL Hanford Group, Inc. \\ Richland, WA 99352 \\ U.S. Department of Energy Contract DE-AC27-99RL14047

$\begin{array}{lll}\text { EDT/ECN: } & & \text { UC: N/A } \\ \text { Cost Center: } & \text { N/A } & \text { Charge Code: } \\ \text { B\&R Code: } & \text { N/A } & \text { Total Pages: } 25\end{array}$ \\ Key Words: 241-AN-102, Corrosion, Probe, MPCMS, Lessons Learned
}

Abstract: This document provides lessons learned for the 241-AN-102 Multi Probe Corrosion Monitoring System (MPCMS) that was installed in Tank 241-AN-102 in May 2008.

TRADEMARK DISCLAIMER. Reference herein to any specific commercial product, process, or service by trade name trademark, manufacturer, or othenvise, does not necessarily constitute or imply its endorsement, recommendation, or favoring by the United States Government or any agency thereof or its contractors or subcontractors.

Printed in the United States of America. To obtain copies of this document, contact: Document Control Services, P.O. Box 950, Mailstop H6-08, Richland WA 99352, Phone (509) 372-2420; Fax (509) 376-4989.
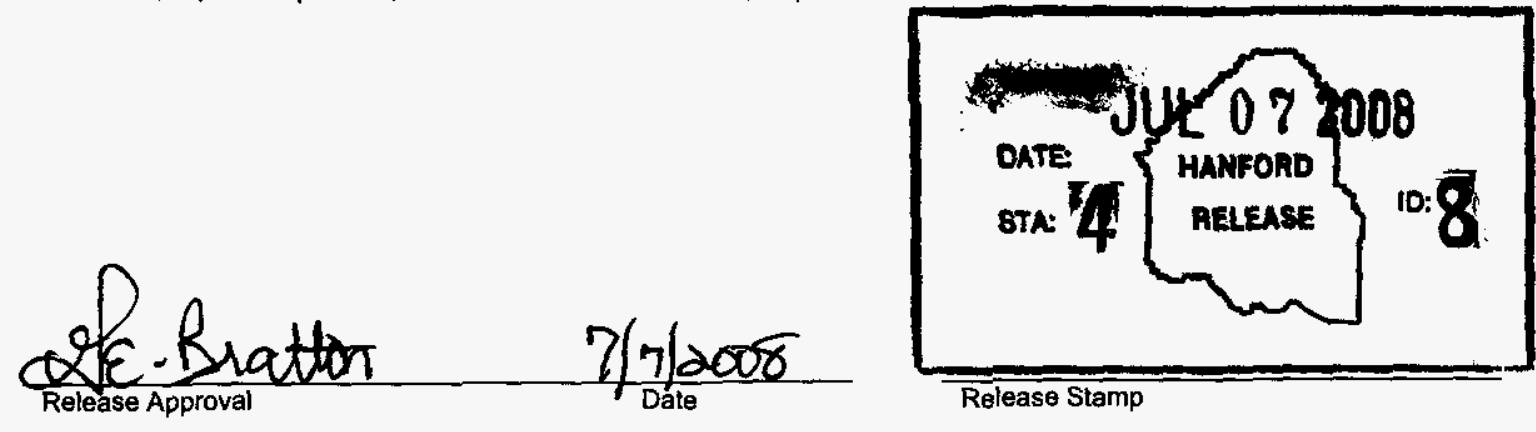

Approved For Public Release 
RPP-RPT-37508, Rev. 0

\section{TANK 241-AN-102 MULTI-PROBE CORROSION MONITORING SYSTEM PROJECT LESSONS LEARNED}

June 2008

prepared by

\section{ARES Corporation}

1100 Jadwin Avenue, Suite 400

Richland, Washington 99352

(509) 946-3300

prepared for

CH2M HILL Hanford Group, Inc. 
RPP-RPT-37508, Rev. 0

TABLE OF CONTENTS

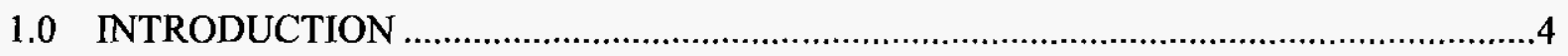

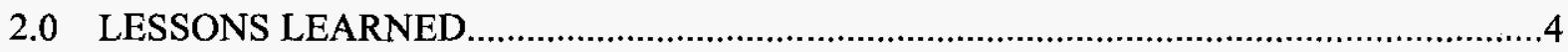

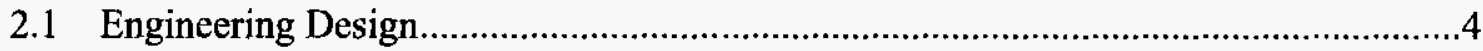

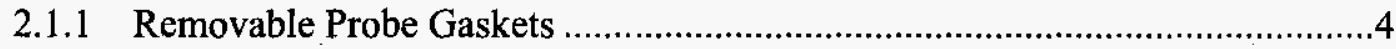

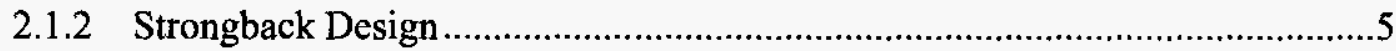

2.1.3 Primary Reference Electrodes.............................................................

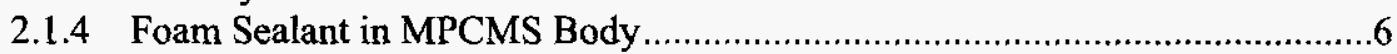

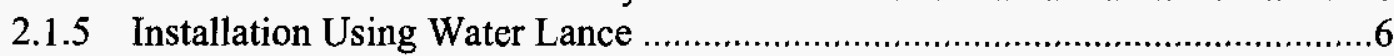

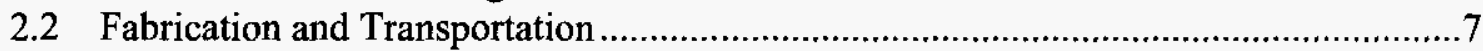

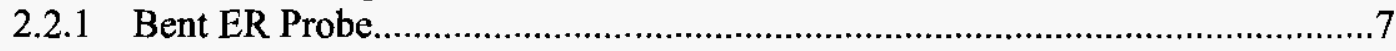

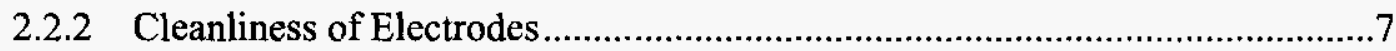

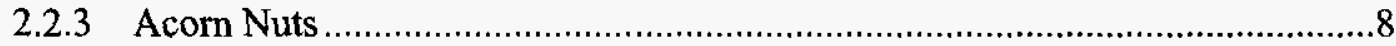

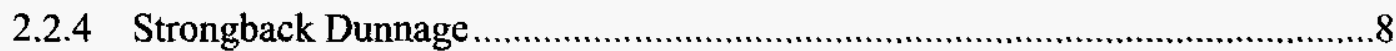

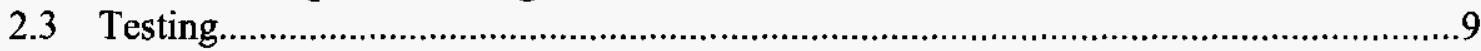

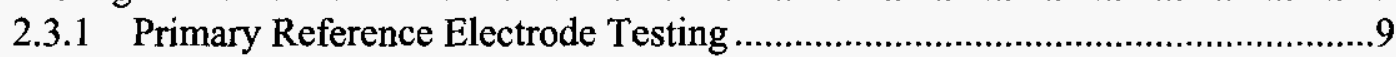

2.3.2 ER Probe Testing ................................................................................ 9

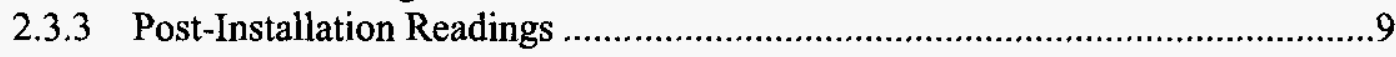

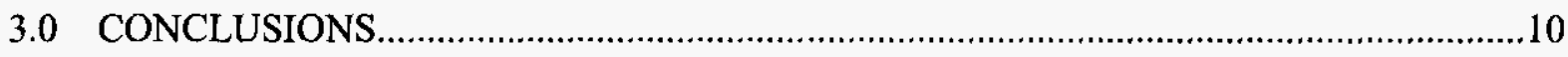

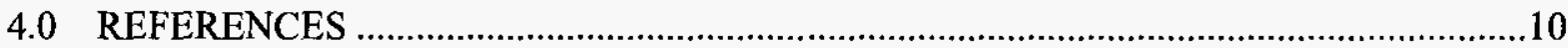

\section{LIST OF APPENDICES}

$\begin{array}{ll}\text { Appendix A - } & \text { Design of Corrosion Probes for 241-AY-102 - AY-102 and AN-102 Design } \\ & \text { Differences Review Meeting Minutes }\end{array}$

Appendix B $\quad$ Fixed Probe Design Improvements 
RPP-RPT-37508, Rev. 0

\section{LIST OF TERMS}

Abbreviations and Acronyms
$\begin{array}{ll}\text { CH2M HILL } & \text { CH2M HILL Hanford Group, Inc. } \\ \text { ER } & \text { Electrical Resistance } \\ \text { MPCMS } & \text { Multi-Probe Corrosion Monitoring System } \\ \text { Units } & \\ \text { ft-lb } & \text { foot pound } \\ \text { in. } & \text { inch } \\ \text { lbf } & \text { pound force } \\ \text { psig } & \text { pound per square inch gauge }\end{array}$




\subsection{INTRODUCTION}

During 2007 and 2008, a new Multi-Probe Corrosion Monitoring System (MPCMS) was designed and fabricated for use in double-shell tank 241-AN-102. The system was successfully installed in the tank on May 1, 2008. The 241-AN-102 MPCMS consists of one "fixed" in-tank probe containing primary and secondary reference electrodes, tank material electrodes, Electrical Resistance (ER) sensors, and stressed and unstressed corrosion coupons. In addition to the fixed probe, the 241-AN-102 MPCMS also contains four standalone coupon racks, or "removable" probes. Each rack contains stressed and unstressed coupons made of American Society of Testing and Materials A537 CL1 steel, heat-treated to closely match the chemical and mechanical characteristics of the 241-AN-102 tank wall. These coupon racks can be removed periodically to facilitate examination of the attached coupons for corrosion damage. Along the way to successful system deployment and operation, the system design, fabrication, and testing activities presented a number of challenges. This document discusses these challenges and lessons learned, which when applied to future efforts, should improve overall project efficiency.

\subsection{LESSONS LEARNED}

Lessons learned have been divided into three main categories: engineering design, fabrication and handling, and testing. Engineering design-related lessons learned cover both engineering documentation requirements and engineering-related issues associated with the function and assembly of the MPCMS. Fabrication and handling lessons learned address issues with the fabricator, equipment, and handling and transportation. Finally, testing lessons learned include issues related to MPCMS testing, both at the factory and following the field installation activities.

\subsection{Engineering Design}

\subsubsection{Removable Probe Gaskets}

The MPCMS includes four removable probes that contain stressed and unstressed corrosion coupons to be forensically examined after time spent in tank waste. During inspections performed after transportation of the MPCMS from the fabricator's facilities to the 200 East area of the Hanford Site, during construction acceptance test activities, it was noted that the gaskets used with the removable probes at the top of the probe assembly had worked loose (become unseated). The interface includes the flat face of the removable probe flange seated on the end of a short stub of $3 \times 2 \times 1 / 8$-in. tube steel that acts as a guide through the fixed probe main flange. A 1/8-in. thick Ethylene Propylene Diene Monomer gasket was used between the two mating surfaces to form a seal. Two 4-1/2-in. long bolts were placed through the removable probe flange and threaded into the top of the fixed probe main flange, providing a tensile connection to hold each removable probe in place (see H-14-107480-1, MPCMS Multi Probe Assembly). When the MPCMS was oriented vertically this design provided adequate support, however, when the assembly was loaded onto the strongback lifting device in the horizontal position, the 
tensile force on the long bolts was not enough to hold the removable probes centered on the tube steel during transport of the assembly. Vibration and jostling on the truck caused the long bolts to bend slightly where they threaded into the main flange, and the removable probes were able to shift downward enough to lose the seal with the gaskets, allowing them to become unseated.

Lesson Learned. A more robust removable probe mounting design should be used for future MPCMS units. A bottom flange should be welded to the $3 \times 2 \times 1 / 8$-in. tube steel to provide a wider, more stable mounting surface. Shorter bolts could then be used to hold the removable probe flange to the bottom flange. This will eliminate unnecessary bending forces on the boits and will more firmly hold the removable probes in place regardless of orientation of the assembly. The use of a bottom flange will also provide a larger surface area for the gasket to seat against.

\subsubsection{Strongback Design}

The strongback lifting device was designed to safely support the MPCMS during transportation and installation activities. Well into fabrication, it was discovered that a clearance problem existed such that two of the removable probes could not be assembled onto the MPCMS while it was loaded onto the strongback. This fitment issue was overlooked during reviews of the drawings prior to fabrication. A last-minute modification was made to the strongback to allow the MPCMS with removable probes to fit properly.

Lessons Learned. Rigorous reviews for not just the technical, but also operational aspects of the components should always be completed prior to final approval of a design. This is especially important when two separate pieces of equipment are shown on separate drawings, but are required to interface together.

\subsubsection{Primary Reference Electrodes}

The MPCMS fixed probe was designed to include three types of primary reference electrodes to facilitate corrosion potential measurements: saturated Calomel electrodes, silver/silver-chloride electrodes, and copper/copper-sulfate electrodes. Double-junction electrodes were required to minimize the risk of contaminating the electrode filling solution with tank waste following immersion in the tank. Commercial "off-the-shelf" versions of these electrodes capable of withstanding the waste tank environment could not be identified. Thus, a supplier capable of developing and providing custom-made, radiation-resistant versions of these electrodes was identified and retained for this purpose. Because the supplier perceived that the waste tank temperature could vary widely, and because standard copper/copper-sulfate electrodes are not stable over a wide range of temperatures, the supplier chose not to supply standard copper/copper-sulfate electrodes. Instead, the supplier provided "hybrid" copper sulfate/silver chloride electrodes (i.e., standard double-junction silver/silver-chloride reference electrodes, but with 1 molar copper sulfate solution instead of saturated potassium chloride as the electrolyte in the secondary (outer) cell). The substitution was not discovered until late in the fabrication process (during factory acceptance testing). Proper replacement electrodes could not be supplied in time to meet MPCMS installation schedule. Thus the hybrid electrodes were used on the 241-AN-102 MPCMS. 
Lessons Learned. While the intent of the electrode supplier was noble, these hybrid electrodes are not appreciably different than the other standard silver/silver-chloride electrodes included on the probe. Additionally, the mixture of filling solutions defeats the purpose of the double-junction design for electrolyte contamination prevention. Better communication with the suppliers and more thorough receipt inspections should be applied to prevent this issue in the future.

\subsubsection{Foam Sealant in MPCMS Body}

The MPCMS used two-part, polyurethane, closed-cell foam to fill the void space in the 2-in. pipe body of the fixed probe. The purpose of the foam is to minimize the effect of a leak should one develop. The foam also minimizes the chance that waste could intrude and be retained in the probe body (complicating removal of the MPCMS from the tank following its useful life). Additionally, the foam protects the wiring leading from the individual electrodes and ER sensors up to the terminal box at the top of the assembly. All the wiring and electrodes were required to be rigorously tested multiple times prior to application of the foam, since foaming virtually eliminates the possibility of replacing an electrode or wire afterward. Pressure testing was also to be completed on the probe body prior to filling it with foam. The components were all successfully tested and the probe was filled with foam as required without issue. However, during shipping one of the ER sensors was damaged (discussed in Section 2.2.1). If the probe were not filled with foam, the damaged ER sensor could have been easily replaced.

Lessons Learned. While the foam is well suited for its intended purpose, repairs and/or alterations to the wiring inside the probe body are prevented once the foam is applied. Future MPCMS units will likely be foam-filled based on the potential risks vs. the benefits afforded by this design feature. Increased emphasis should be placed on preventing shipping and handling damage since the foam filling prevents most repairs on components using internal wiring.

\subsubsection{Installation Using Water Lance}

Tank 241-AN-102 has a layer of solids in the bottom with a hard saltcake crust which the MPCMS needed to penetrate during installation into the tank. To help prevent damage during installation, several features were incorporated into the MPCMS design to help break through the hard solids layer, including an integrated water lance. The water lance was designed to spray approximately 30 gallons per minute at 100 psig, with a full circular spray area and a spray angle of approximately 80 degrees. The water lance was successfully operated during the installation process, which took approximately 1 hour and 900 gallons of water. However, the manner in which it was used may not have been optimal. During installation, the MPCMS was slowly lowered into the tank until it hit the hard crust, allowing no more than $100 \mathrm{lbf}$ of the weight to unload from the crane tension (via a dynamometer). It was held there with the water lance running for a few minutes, then lowering was resumed. While this method worked, faster dissolution of the crust was obtained by raising the probe up (after reaching the $100 \mathrm{lbf}$ stopping point in the crust), running the water for several minutes, then resuming the lowering of the probe. Because of the spray angle of the water lance, a minimum of 7-in. to 12-in. of distance is 
required from the tip of the lance to the crust layer in order to affect the solids for a circular area 11 -in. in diameter (the outer diameter of the MPCMS assembly due to the removable probes).

Lessons Learned. Raising the MPCMS assembly up and holding for a few minutes after hitting the hard crust appeared to produce the best gains during installation. This is a logical technique given that the spray angle of the water lance would require some spacing between the tip and the hard surface to affect a circular area large enough for the MPCMS to pass through. Had this cyclic method of raising and lowering the probe to steadily drive it through the saltcake been used the whole time, the probe may have been installed more quickly and with less water. Future installations may benefit by applying this technique

\subsection{Fabrication and Transportation}

\subsubsection{Bent ER Probe}

During transport of the MPCMS from the fabricator to the Hanford Site, the lowermost (i.e., saltcake layer) ER sensor was slightly damaged (bent). Engineers from the MPCMS design team inspected and tested the ER sensor after delivery of the system and discovery of the damage. Testing indicated that the ER sensor was still functioning properly. However, it was discovered that the bending of the ER sensor had produced a slight separation between glass and metal at the glass-to-metal interface at the base of the ER sensor. This separation appeared to be superficial in nature (i.e., did not appear to penetrate all the way into the probe body), but as a precaution against the potential for waste in-leakage (and since replacement was not an option), a small amount of radiation-resistant epoxy was applied to fill the separation at the glass-to-metal interface at the base of the ER sensor. It is not known exactly when or how the damage to the ER sensor occurred. The design included a steel bar to act as guard over the top of the electrodes, however the sides were open and hands or objects could have potentially contacted the ER sensor from the side.

Lessons Learned. Future corrosion probes should include measures to go "above and beyond" those which have historically been considered adequate in an effort to protect the MPCMS components from damage. Guards that protect the components not only from the top, but also from the sides, should be designed and used. It will most likely be required to remove such guards just prior to installation in the tank. This will also require care by all parties handling the equipment to ensure the guards are used according to the design intent.

\subsubsection{Cleanliness of Electrodes}

The secondary reference electrodes each used a glass-to-metal feedthrough for isolation from the probe body. These feedthroughs each mounted to the probe via a $1 / 8$-in. National Pipe Thread (NPT) connection. In order to create a seal, Grafoil $\left({ }^{1}\right.$ thread sealant was used on the threads. This is a nuclear grade, graphite-based thread sealant paste. Use of the thread sealant on such

\footnotetext{
${ }^{1}$ Grafoilß is a registered trademark of GrafTech International Holdings, Inc.
} 
small threads tended to result in excess sealant being applied which then smeared around the general area. This thread sealant is electrically conductive; thus it would be possible to short the electrode to the feedthrough body through carelessness, or through the use of excess sealant. This scenario was assumed to be the cause of an electrical short identified between electrode and probe body as noted during construction acceptance testing (RPP-RPT-37504, Construction Acceptance and Process Test Report for the 241-AN-102 Multi-Probe Corrosion Monitoring System). In general, the overall cleanliness of the electrodes and connection areas could have been greatly improved by rinsing each electrode and connection area with acetone or isopropyl alcohol and wiping with a clean white cotton cloth following installation.

Additionally, during the fabrication of the MPCMS each electrode had to be handled a number of times, both for installation onto the probe body and for testing activities. The Vapor Corrosion Inhibiting paper that was applied to the electrodes by the manufacturer was removed when required by testing, then reinstalled following the activity. This resulted in significant wear and degradation to the Vapor Corrosion Inhibiting paper. A good practice would be to replace the Vapor Corrosion Inhibiting paper with new paper each time it was removed, and to tape seal the new paper in place to the probe body.

Lessons Learned. Electrodes and feedthroughs should be cleaned directly following installation by thoroughly rinsing with acetone and wiping up excess thread sealant with a clean white cotton cloth. The Vapor Corrosion Inhibiting paper should also be replaced each time it is removed with new paper and tape sealed to the probe body. This will help ensure the integrity of the electrode during fabrication and testing activities.

\subsubsection{Acorn Nuts}

Acorn nuts were specified to hold the round and bar coupons in place on the MPCMS. During fabrication, it was discovered that the acorn nuts procured could not withstand any reasonable amount of torque (less than $1 \mathrm{ft}-\mathrm{lb}$ ) before the stud would push through the top of the nut. The acorn nuts were replaced with deformed thread locknuts (Grainger part no. 2GB43). The deformed thread locknuts were found to hold very well, and came from the manufacturer with a beveled edge (a bevel had to be machined into the acorn nuts prior to their use).

Lessons Learned. The deformed thread locknuts were found to work perfectly for the MPCMS applications. Use of them eliminates the extra time required for machining a beveled edge, as well as eliminating special torque requirements to ensure they stay in place properly.

\subsubsection{Strongback Dunnage}

The strongback was designed so that the spray ring could be assembled onto the MPCMS, and the entire MPCMS assembly loaded onto the strongback. This facilitates installation of both the spray ring and MPCMS into the tank in a single lift. When loaded onto the strongback, the spray ring and portion of the MPCMS inside the spray ring were cantilevered from the dowel pins beyond the strongback top plate. Structurally the MPCMS was designed to withstand the bending stresses induced from the cantilevered load, however as a precaution recommendations were made in RPP-RPT-36802, Recommendations for Handling and Storage of the 241-AN-102 
Multi-Probe Corrosion Monitoring System (MPCMS), for dunnage or other supplemental support to be used under the spray ring during transportation. These recommendations were not heeded, likely resulting in the failure of the gaskets at the top of the removable probes as described in Section 2.1.1.

Lessons Learned. An integrated support structure should be designed within the strongback to provide support for the cantilevered section of the MPCMS and the spray ring. This will provide an additional level of confidence that the assembly will be loaded and transported correctly following the handling recommendations made by engineering.

\section{$2.3 \quad$ Testing}

\subsubsection{Primary Reference Electrode Testing}

Original specifications for testing of the primary reference electrodes called for the preparation of a salt solution and submersion of part of the electrode to perform the test. While acceptable, this practice would have greatly complicated testing after installation to the probe body and would have subjected the electrodes to unnecessary handling. A new method was developed which used a cotton ball soaked in the salt solution to act as a conductive bridge between the primary reference electrode and the test component (either a commercially available reference electrode or piece of tank steel). This method gave the same results as immersion without the additional handling or manipulation of the electrode.

Lessons Learned. Testing procedures should maximize the survivability of the items they are intended to test, and be simple to perform.

\subsubsection{ER Probe Testing}

Testing of the ER probes installed on the MPCMS was originally specified to use the warmth of a hand to verify functionality. This produced erratic results, and the procedure was revised to use a heat gun for more consistent results. Inconsistent readings were eliminated during testing with this new methodology.

Lessons Learned. Using variable equipment for testing results in problems with repeatability and verification. Standardized equipment allows for more consistent results. Future testing of this same kind should specify a heat gun in the procedures in lieu of the warmth of a hand.

\subsubsection{Post-Installation Readings}

After the installation of the MPCMS into double-shell tank 241-AN-102, technicians manually measured the potentials of the electrode pairs on a daily basis through the first month, and with decreasing frequency afterwards. These readings, while generally consistent, contained a number of erratic readings that were often orders of magnitude different from established potentials. It is likely that these erratic readings are the result of measurement errors made by the instrument technicians. 
Lessons Learned. Manual data retrieval should only be used if absolutely required. In future corrosion probes, an automated portable data collection unit should be fabricated which would allow for more consistent readings, better error checking, and more consistent sampling.

\subsection{CONCLUSIONS}

Despite the relatively minor problems encountered during design, fabrication, and installation, the 241-AN-102 MPCMS, the system is a success in terms of design input, function, and the data being produced (RPP-RPT-37746, 241 AN 102 Multi-Probe Corrosion Monitoring System:

Evaluation of First 30 Days of Data). Improvements over the 241-AN-107 IMCP that have been integrated into the 241-AN-102 MPCMS are outlined in Appendix A. The MPCMS platform installed in 241-AN-102 will serve as the basis for future MPCMS designs. Lessons learned during the development of the 241-AN-102 MPCMS should improve the development of future similar systems, and these improvements are outlined in Appendix B as they apply to the 241-AY-102 MPCMS

\subsection{REFERENCES}

Drawing H-14-107480, Sheet 1, MPCMS Multi Probe Assembly, Revision 1, CH2M HILL Hanford Group, Inc., Richland, Washington

RPP-RPT-36802, Recommendations for Handling and Storage of the 241-AN-102 Multi-Probe Corrosion Monitoring System (MPCMS), Revision 0, CH2M HILL Hanford Group, Inc., Richland, Washington.

RPP-RPT-37504, Construction Acceptance and Process Test Report for the 241-AN-102 MultiProbe Corrosion Monitoring System, Revision 0, CH2M HILL Hanford Group, Inc., Richland, Washington.

RPP-RPT-37746, 241 AN 102 Multi-Probe Corrosion Monitoring System: Evaluation of First 30 Days of Data, Revision 0, CH2M HILL Hanford Group, Inc., Richland, Washington. 
RPP-RPT-37508, Rev. 0

APPENDIX A

DESIGN OF CORROSION PROBES FOR 241-AY-102 - AY-102 AND AN-102 DESIGN DIFFERENCES REVIEW MEETING MINUTES 


\section{MEETING MINUTES}

\section{A RE 5}

COAFDATION

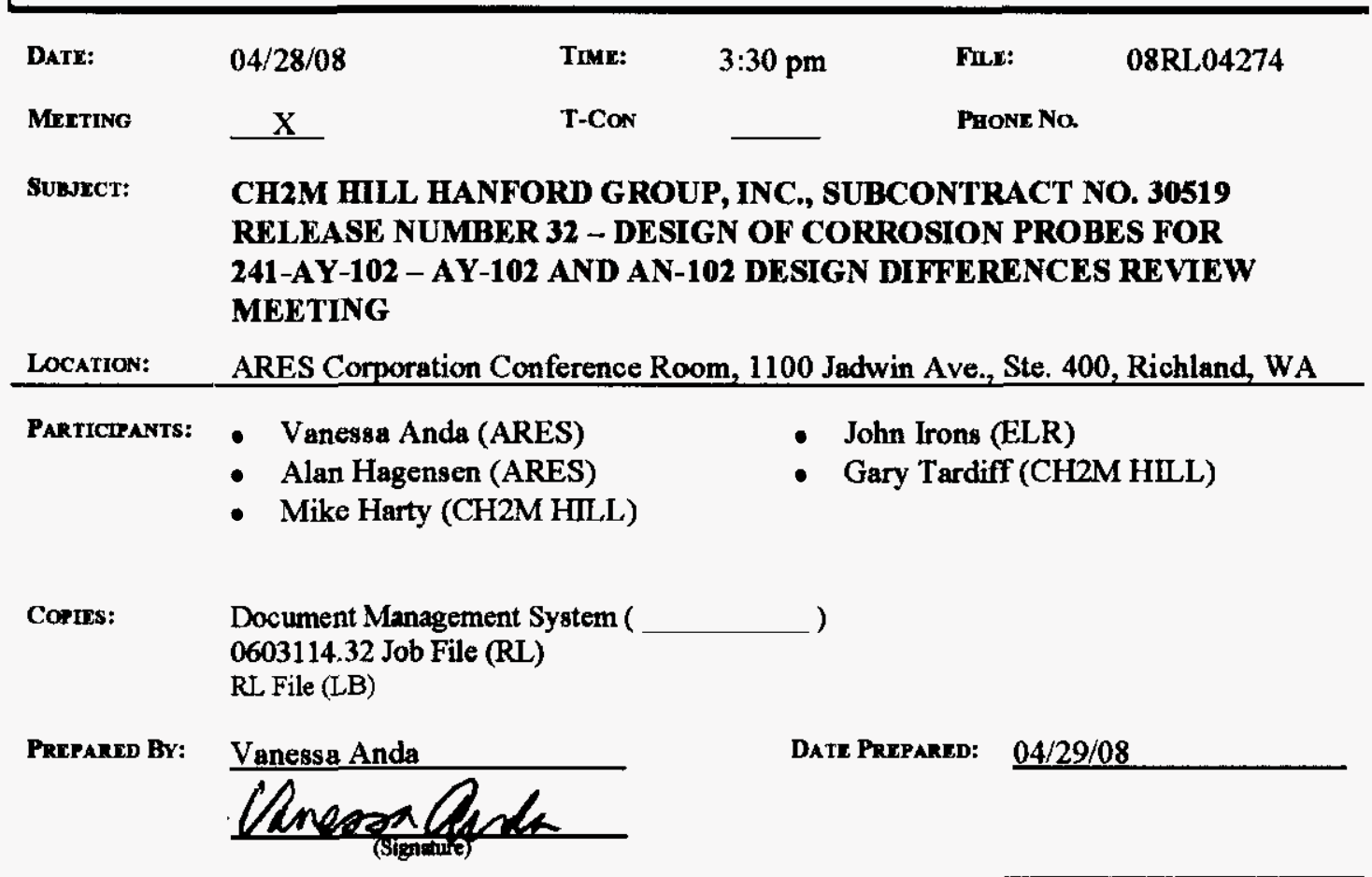

This meeting was held to present the design differences between the 241-AY-102 Multi-Probe Corrosion Monitoring System (MPCMS) and the 241-AN-102 MPCMS design. The drawing series was reviewed to present incorporation of redlines generated and lessons learned during fabrication of the 241-AN-102 MPCMS. Several other items of interest were also discussed during the review meeting and are summarized below.

The 241-AY-102 MPCMS drawings presented included:

- H-14-107561, Sheet 1, Rev. 0, AY102 MPCMS Drawing List \& Vicinity Map;

- H-14-107562, Sheet 1, Rev. 0, AY102 MPCMS 241-AY-102 Multi Probe Installation;

- H-14-107563, Sheet 1, Rev. 0, AY102 MPCMS Multi Probe Assembly;

- H-14-107564, Sheet 1, Rev. 0, AY102 MPCMS Fixed Probe Notes and Parts List;

- H-14-107564, Sheet 2, Rev. 0, AY102 MPCMS Fixed Probe Assembly;

- H-14-107564, Sheet 3, Rev. 0, AY102 MPCMS Fixed Probe Details;

- H-14-107564, Sheet 4, Rev. 0, AY102 MPCMS Fixed Probe Details;

- H-14-107564, Sheet 5, Rev. 0, AY102 MPCMS Fixed Probe Details;

- H-14-107564, Sheet 6, Rev. 0, AY102 MPCMS Fixed Probe Details;

- H-14-107565, Sheet 1, Rev. 0, AY102 MPCMS Removable Probe Assembly;

- H-14-107565, Sheet 2, Rev. 0, AY102 MPCMS Removable Probe Details;

- H-14-107566, Sheet 1, Rev. 1, AY102 MPCMS Details;

- H-14-107567, Sheet 1, Rev. 0, AY102 MPCMS Spray Ring Assembly;

Page 1 of 8 
- H-14-107567, Sheet 2, Rev. 0, AY102 MPCMS Spray Ring Detalls;

- H-14-107568, Sheet 1, Rev. 0. AY102 MPCMS Lifting Assembly Notes and Parts List:

- H-14-107568, Sheet 2, Rev. 0, AYJ02MP'CMS Lifting Assembly; and

- H-14-107569, shect 1, Rev. 0, AYI02 MPCMS Multi Probe tilectrical.

The design dillerences between the AY-102 MPCMS and the AN-102 MPCMS were summarized in a table which was presented and discussed. The table, included in the minutes as Table 1 (241-AY-102 and 241-AN-102 Design Differences), has been modified slightly to include drawing references for design change illustration as requested by Mr. Mike Harty during the meeting. lable 1 is provided on pages 7 and 8 .

Points of discussion that ensued during the review of Table 1 and the drawings are as follows:

1. Mr. Mike Harty asked if movement of the sludge region coupons to the other side of the probe would make the probe harder to construct and if there would be interference between the coupons on the backside of the probe and the strong back. Mr. $\Lambda$ lan Hagensen indicated the coupons were installed on a bar that is welded onto the probe; thus, fabrication should not be more difficult. Additionally, Mr. IIagensen indicated due to the small size of the coupons and the fact that the sludge region ER sensor and primary and secondary reference electrodes are opposite the coupons, strong back interference should not be a problem. During the discussion, a suggestion was made to revisit the method of coupon bar installation; i.e., attach the coupon bars in the vapor space, supernatant, and sludge region using weld studs and nuts as opposed to welding the coupon bars to the fixed probe. This design change will be made to the fixed probe and requires the coupon hars to be lengthened, holes to be drilled through the coupon hars, and extra weld studs and nuts to be added to the parts list for the fixed probe. Further discussion regarding this issue identified the fixed probe body may still need to be cut up in pieces if interest exists in looking at the end state of the primary and secondary reference electrodes in the lab following fixed probe removal. Mr. Harty took the action to ask Mr. Jim Duncan if he would want to review the end state of the primary and secondary reference electrodes following fixed probe removal.

2. The blasting and painting requirements for the strong back were discussed. Mr. Irons raised questions regarding blasting and painting of the strong back. The discussion centered on the blast specification being excessive as the strong back will not see excessive use. Mr. Ilarty mentioned rust or other blemishes on the strong back may raise questions whether the strong back is fit for use. The blasting and painting requirements (NACE \#1/SSPC-SP'5 White Metal Finish and $A$ meron Dimetcote primer) were contained in the 241-AY-102 MPCMS procurement specification document and will remain as they are on the drawings.

3. Mr. Inarty asked about the requirements for heat treating the AAR TC-128 Grade B steel tank car plate. The AAR TC-128 Crade $B$ tank car pieces on the Hanford site need to be cut and prepared prior to fabrication of coupons but may have lead paint due to the age of the pieces. Previously, ARFS had compiled a heat treatment statement of work for the tank car plate. Heat treatment of the tank car steel plate was originally proposed to normalize the AAR TC128 Grade B plate to make it meet the mechanical property 
requirements [yield strength $\left(\sigma_{y}\right)$, and UTS] of ASTM A515-67 Grade 60. Normalizing and associated activities were to be performed on a "best effort" basis and to be considered successful once the plate pieces strips met the yield strength and UTS requirenents of ASTM A515-67 Grade 60. Mr. Harty requested that ARFS determine where to capture heat treating of the $\Lambda \Lambda R T C-128$ Grade $B$ tank car plate, if still required.

4. Mr. Irons mentioned that the fitters in the field had added elbows to the AN-102 MPCMS water lance piping to allow connection of the raw water hose to the water lance and questioned whether ARES could change the conliguration of the water lance end for the AY-102 MPCMS so that the fitters would not have to add elbows, etc., to allow connection of a hose. Mr. Harty indicated that he would like to see these features included in the design of the $\triangle \mathrm{Y}-102 \mathrm{MPC} M S$ water lance. The water lance design will be updated to include two elbows, a piece ol pipe, and an end fitting to allow connection of a water hose. The final configuration of the probe will be shown on the design media with a cap or plug in the end of the pipe with the hose fitting.

5. Mr. Harty requested a reference to the Shipping and Handling document be added to the AY-102 Drawing I ist \& Vicinity Map (H-14-107561-1). A document reference will be added. $\Lambda$ document reference will also be added to the $\Lambda Y 102$ MPCMS Lifting Assembly Notes and Parts List (II-14-107568-1).

6. Mr. Harty asked if a separate $\triangle Y-102$ MPCMS strong back was required or if the AN-102 MPCMS strong back could be reused. Several diflerences were identilied during the discussion to justify design and fabrication of a strong back lor the AY-102 MPCMS. Differenoss that require strong back redesign include: the AY-102 MPCMS is longer than the $\Lambda \mathrm{N}-102 \mathrm{MPCMS}$, the $\Lambda Y-102 \mathrm{MPCMS}$ has a 16" flange and requires different dowel pin placement, the AY-102 MPCMS redesign includes a larger strong back flange support plate with holes drilled thru for support bolt installation, the AY-102 MPCMS supports are in different places than the $A N-102$ MPCMS supports, and the $\Lambda Y-102 \mathrm{MPC} M S$ strong back was designed to a different specification than the $\Lambda \mathrm{N}-102$ MPCMS strong back. Mr. Ilagensen mentioned the AN-102 MPCMS strong back and the AY-102 MPCMS strong back design could be submitted to the selected fabricator with direction to refurbish the $\Lambda \mathrm{N}-102$ strong back to match the $\Lambda Y-102$ strong back design; however, the AN-102 strong back would pretty much be rebuilt.

7. Mr. Irons mentioned that the AN-102 MPCMS, once loaded on the truck for shipping did not have any support under the spray ring canister, in spite of the direction provided in RPP-RPT-36802, Recommendations for IIandling and Storage of the 241-AN-102 Multi-Probe Corrosion Monitoring System (MPCMS), and consequently the canister was exposed to transport vibration. $\Lambda$ request was made to design a strong back extension or a portable dunnage device to support the spray canister during transport on the truck. A spray ring canister support device for shipping will be designed and added to the AY-102 MPCMS design drawings. 
RPP-RPT-37508, Rev. 0

08RL04274

8. It was briefly mentioned that the $\Lambda Y-102$ MPCMS strong back design had changed slightly to include gusset plates as a result of different design methods used for the $\Lambda \mathrm{N}-102$ MPCMS strong back (RPP-8360, Liffing l'oint Evaluation I'rocess, and $\mathrm{AISC}$ 1989 ) and the AY-102 MPCMS strong back (ASME BTII-1-2005, Design of Below-lheHook Lifting Devices). No action is required from this discussion; the reason for the strong back change was just clarified to alleviate concerns related to installation of the AN-102 MPCMS using the previous strong back device.

9. Mr. Harty asked if some design modification could be made to the probe to allow dynamic loading greater than $100 \mathrm{lbs}$. Concerns were expressed indicating it would be hard to monitor/ensure the loading on the $\Lambda \mathrm{N}-102 \mathrm{MPCMS}$ would be kept below 100 lbs during probe installation. Mr. Itarty would like to see a slightly higher allowable load during installation, i.c., 300-500 lhs. Mr. Hagensen indicated the current structural calculation may be conservative in that it only evaluated a 2 " 60 -foot pipe without the benefit of the $25^{\circ} 10^{\prime \prime}$ fins or the water lanee pipe which is supported by stand-offs welded to the 2" pipe. The structural evaluation will be reviewed to determine if the calculation can be refined and to evaluate if design changes could be made to reduce the potential probe bending which would allow additional dynamic loading.

10. Mr. IIarty asked if the AN-102 MPCMS was to be redesigned, if Mr. Ilagensen would still foam the probe. Mr. Hagensen indicated that an expanded discussion of the limitations of probe repair and manipulation following foaming, as related to the AN-102 MPCMS SS-ER sensor damage would be included in the lessons leamed document for the AN-102 MPCMS. A brief discussion ensued related to the benefits of foaming and alternatives that were considered prior to completion of the AN-102 MPCMS design, i.e., probe pressurization or maintenance of a vacuum. No action is required from this discussion, ARES will document in lessons learned document.

11. Mr. Harty indicated that field personnel had recommended for future designs the lower removable probe guide fins be tapered on both sides to case insertion and removal. The current $A N-1(12$ and $A Y-102$ MPCMS designs have the removahle probe guide fins tapered on the top side and flat on the bottom side. Mr. Hagensen indicated the riser the AY-102 MPCMS will be installed in is a larger riser than the AN-102 MPCMS (16" versus 12"); thus, insertion of the probe should not be a problem. Redesign of the removable probe guides fins to taper both sides to ease insertion will not be performed. No action is required from this discussion; however, future designs will include guide fins that are tapered both top and bottom.

Redlines generated during the fabrication of the $\Lambda \mathrm{N}-102 \mathrm{MPCMS}$ that were incorporated in the AY-102 MPCMS design were brielly discussed during the meeting and are summarized in the bulleted list which follows:

\section{AN-112 Corrosion Probe Redlines Incorporated in the AY-112 Corrosion Probe}

- $1 / 4$ " high lettering for probe label

- Provided direction for bar coupon cleaning

- Acorn nuts replaced with deformed thread locknuts

- Primer Ameron Dimetcole 9VOC 
- Fabricator allowed to drill probe body $1 / 8$ " larger than coupling ID

- $\Lambda$ dded flag note to plug the TB fitting following foaming and the final continuity check

- Add flag notes regarding design temperatures and pressures of the water lance piping and the spray nozzle piping

- $\Lambda$ dded a TB fitting, a conduit plug, an UHMWPE leak detection cable holder, and two check valves (part number U3HCSBN.500SS) to the fixed probe

- Changed part description for the CUSO4 primary reference electrode (Item 66) to double-junct. CUSO4 (II-14-107564-1)

- Fixed probe spray ring quantity changes and part additions

- Fixed probe tip radiused

- Fixed probe ER sensor mount moditied

- Fixed probe primary reference electrode mount modified

- Hixed probe water lance clbow dimensioned

- Removable probe table addition for recording removable probe coupon weights

- Removable probe bar coupons in line with the other coupons

- Upper spray ring orientation changed to from vertical to horizontal

- Strong back clamps added to strong back assembly

- Strong back guide plate size moditied

- Strong back guide blocks modified for clamps

- $\Lambda$ ddition of a third terminal block

- Expansion of the ER receptacles wiring diagram

- Ise of the 'Trace-'Tek jumper cable supplied with the instrument

Only one redline that was generated during the fabrication of the AN-102 MPCMS was not incorporated in the $\Lambda Y-102$ MPCMS design. The $\Lambda \mathrm{N}-102 \mathrm{MPCMS}$ design included a plug gauge. A plug gauge was not added to the AY-102 MPCMS design since Riser 73, the corrosion probe riser, is a $16^{\prime \prime}$ riser and the corrosion probe was designed to fit in a 12 " riser.

Following the presentation of the design media and discussion, Mr. Harty indicated he would prefer to see the changes identified be made prior to final design release (originally scheduled for $\Lambda$ pril 30,2008 ). Mr. Harty asked that $\Lambda$ RES provide an estimate of the additional time required to update the design media to reflect the desired changes.

Discussions amongst ARFS personnel regarding schedule and availability for redesign indicate efforts to complete the actions identified in the $\Lambda$ ction Status lable below may take approximately three weeks, which moves the design completion date from $\Lambda$ pril 30,2008 , to May 21, 2008. $\Lambda$ RES will evaluate the change to the project estimated actual cost $(\mathrm{E} \Lambda \mathrm{C})$ and provide it to CII2M IIILL separately. 
RPP-RPT-37508, Rev. 0

08RL04274

Action Status Table.

\begin{tabular}{|c|c|c|c|}
\hline Action & $\begin{array}{c}\text { Responsible } \\
\text { Person }\end{array}$ & Stulus & Comments \\
\hline $\begin{array}{l}\text { 1. Redesign coupon bar attachment } \\
\text { for the fixed corrosion probe }\end{array}$ & ARES & Open & \\
\hline $\begin{array}{l}\text { 2. Determine intercst in revicwing } \\
\text { the status of the primary and } \\
\text { secondary reference electrodes }\end{array}$ & W.M Harty & Open & \\
\hline $\begin{array}{l}\text { 3. Determ ine heat treat rcquirement } \\
\text { for the AAR TC-128 Crrade } B \\
\text { stecl tank car plate and wherc to } \\
\text { capture it in the AY } 102 \\
\text { MPCMS design media }\end{array}$ & ARES & Open & \\
\hline $\begin{array}{l}\text { 4. Updnte waler lance design to } \\
\text { include clbows, pipe, a hose } \\
\text { fitting and a plug for the final } \\
\text { configuration }\end{array}$ & ARTSS & Open & \\
\hline $\begin{array}{l}\text { 5. Add a reference } 10 \text { the } A Y-1112 \\
\text { MTCMS shipping and handling } \\
\text { document to Drawings } \\
\text { H-14-107561-1 and } \\
\text { H-14-107568-1 }\end{array}$ & $\Lambda \mathrm{RI}$ iS & (Ten & \\
\hline $\begin{array}{l}\text { 6. Design a spray ring canister } \\
\text { support device for shipping of } \\
\text { the AY-102 MPCMS }\end{array}$ & $\Lambda \mathrm{RFS}$ & Open & \\
\hline $\begin{array}{l}\text { 7. livaluale struclural evaluations to } \\
\text { determ ine if the calculation can } \\
\text { be refined to allow additional } \\
\text { dynamic loading or determine if } \\
\text { design changes could be made to } \\
\text { allow additional loading during } \\
\text { installation }\end{array}$ & ARliS & ()pen & \\
\hline $\begin{array}{l}\text { 8. Polyurethane foam installation } \\
\text { for fixed probe }\end{array}$ & ARES & Open & $\begin{array}{l}\text { Add to AN-102 MPCMS lessons } \\
\text { learned }\end{array}$ \\
\hline
\end{tabular}


RPP-RPT-37508, Rev. 0

志

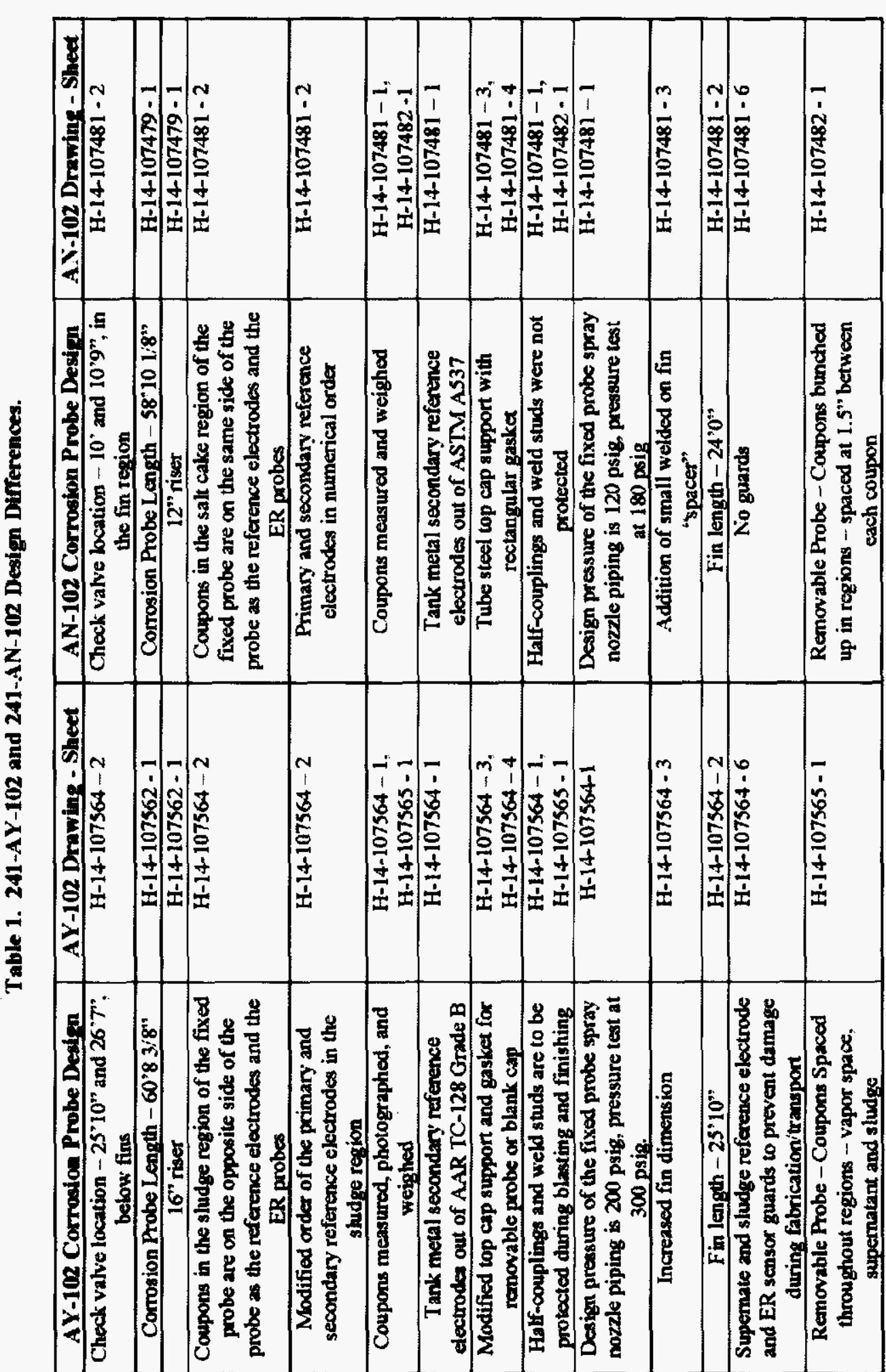


RPP-RPT-37508, Rev. 0

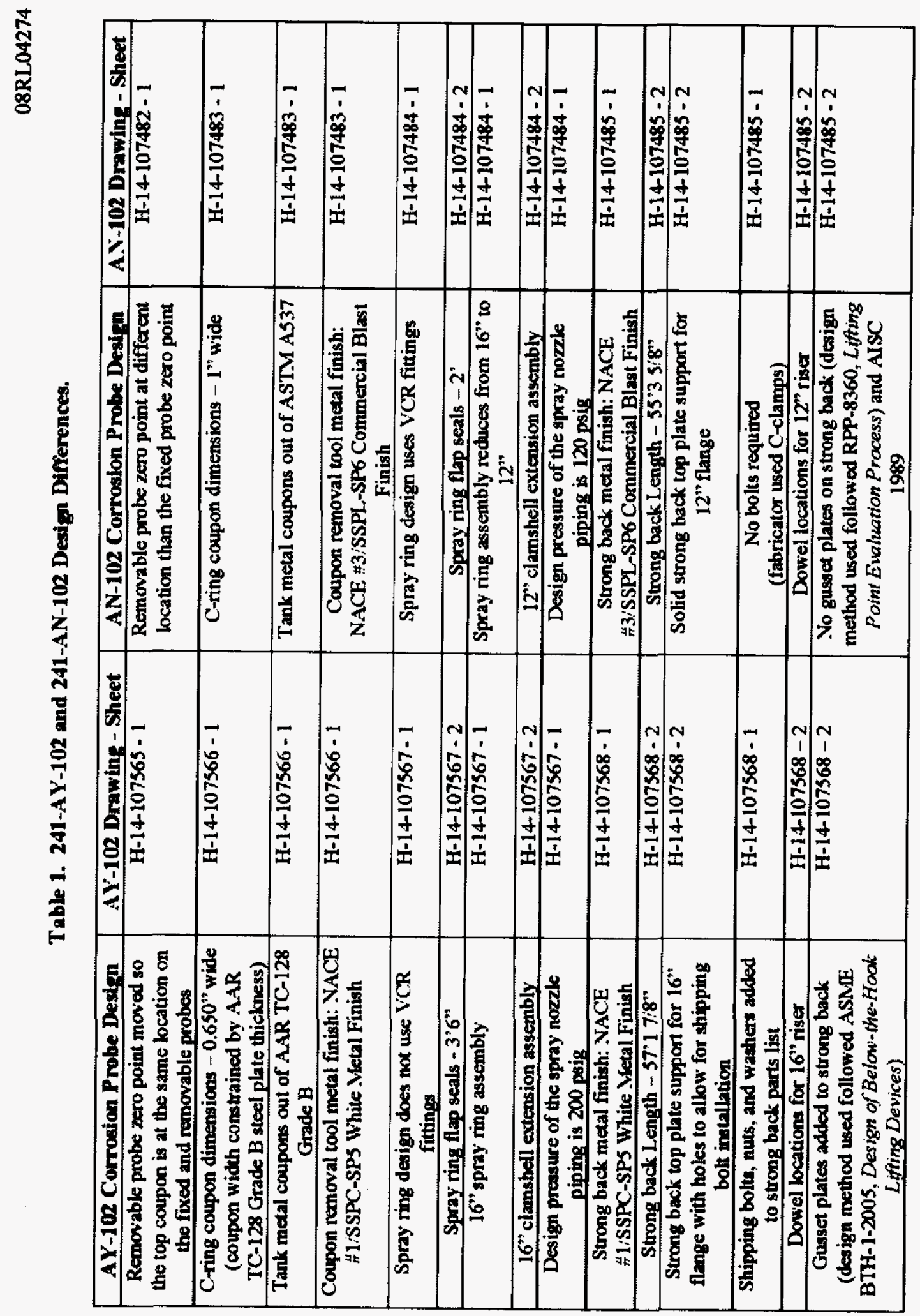


RPP-RPT-37508, Rev. 0

APPENDIX B

FIXED PROBE DESIGN IMPROVEMENTS

B-1 
RPP-RPT-37508, Rev. 0

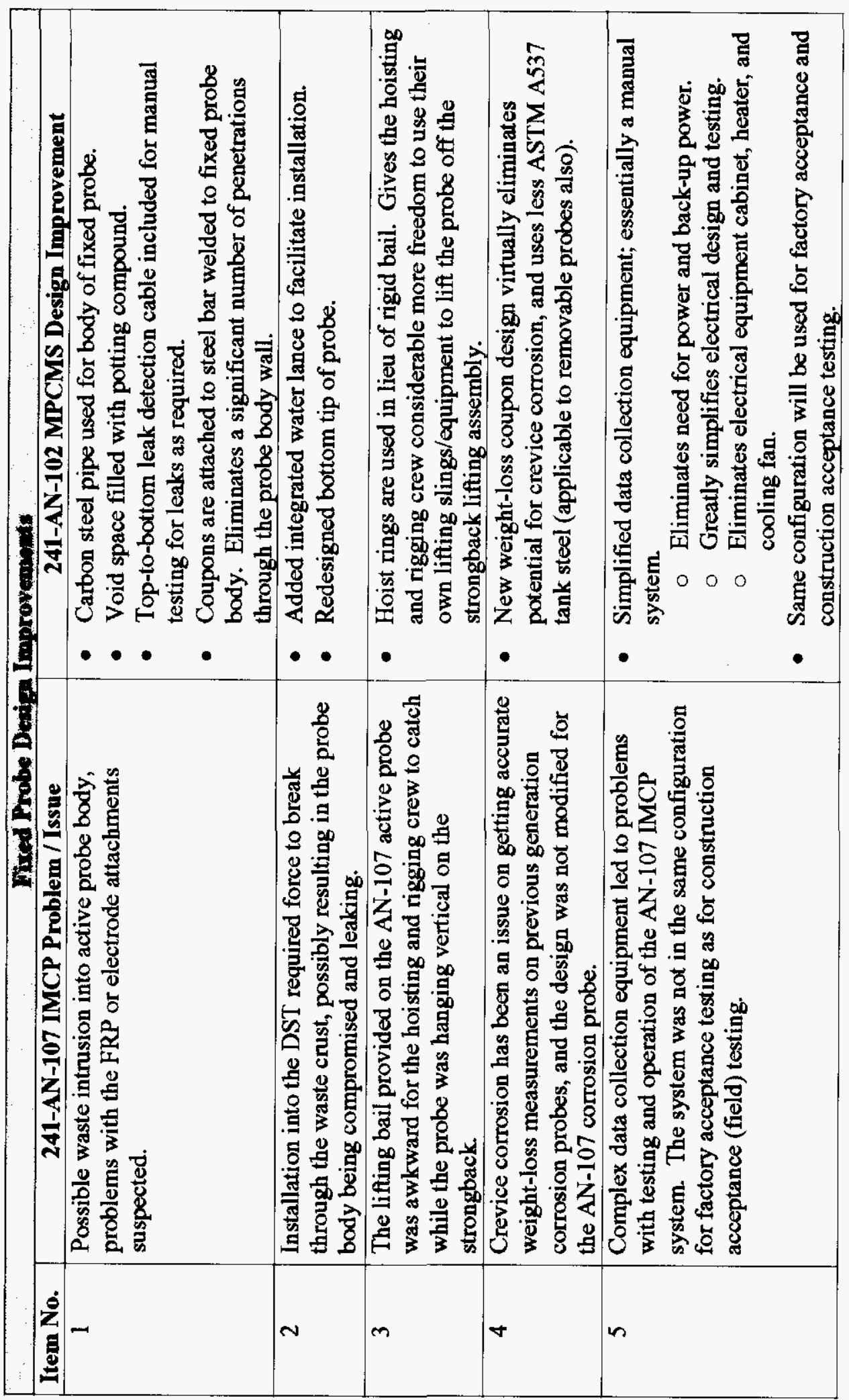

B-2 
RPP-RPT-37508, Rev. 0

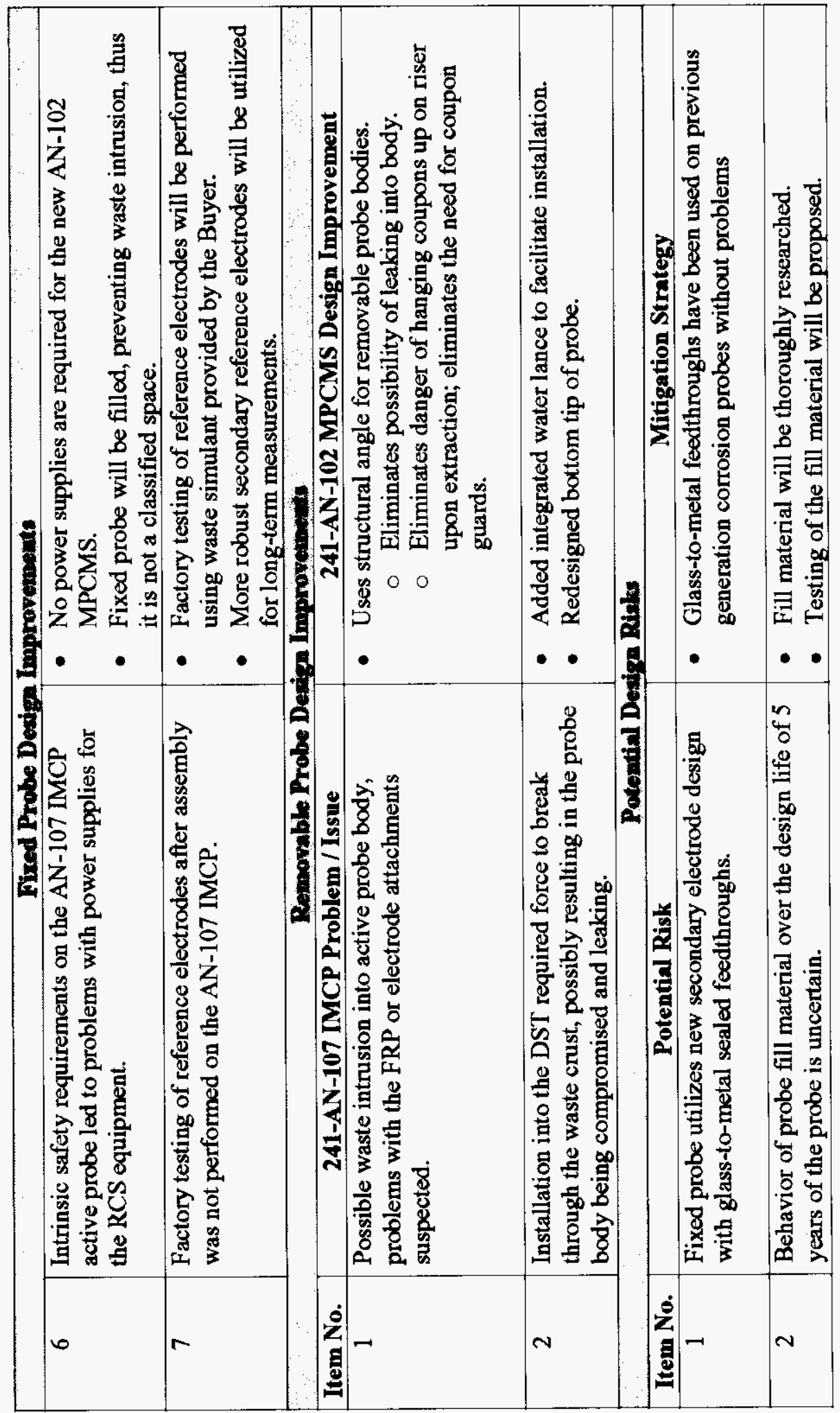

B-3 